$6 \mid 2010$

Varia

\title{
Complice, confidentiel, simultané
}

\section{Ole Robert Sunde}

Traducteur : Karin Holter

\section{Q OpenEdition \\ Journals}

Édition électronique

URL : http://journals.openedition.org/ccs/688

DOI : $10.4000 /$ ccs.688

ISSN : 2558-782X

\section{Éditeur :}

Presses universitaires de Rennes, Association des lecteurs de Claude Simon

\section{Édition imprimée}

Date de publication : 31 décembre 2010

Pagination: 169-171

ISBN : 9782354120771

ISSN : $1774-9425$

\section{Référence électronique}

Ole Robert Sunde, «Complice, confidentiel, simultané », Cahiers Claude Simon [En ligne], 6 | 2010, mis en ligne le 21 septembre 2017, consulté le 14 septembre 2020. URL : http://journals.openedition.org/ $\operatorname{ccs} / 688$

Cahiers Claude Simon 


\section{Complice, confidentiel, simultané}

Par Ole Robert SUNDE

Le livre de Claude Simon, Histoire, a été traduit en norvégien en 1968, une année après sa sortie en France ; Carl Hambro, son traducteur a écrit une préface à l'intention de ceux qui vont s'aventurer dans le roman, c'est à peine une préface et, comme telle, très inhabituelle en tant que paratexte d'un livre ; cette préface minimale consiste tout simplement en un conseil, un conseil pédagogique de lecture, à savoir qu'il faut se servir de ses sens plus que de son intellect... " dans la mesure où les associations et les sauts de description de l'auteur se comprennent mieux par des sens éveillés que par un intellect aigu »; le traducteur n'a pas tort, mais comment est-il possible de se dépouiller de son intellect ? Et pourquoi l'intellect ne serait-il pas mis à contribution dans l'étude d'Histoire et dans l'examen des phrases longues et ondoyantes de Simon ? Tout de suite, nous voici in medias res: le livre ouvre sur des minuscules, et c'est comme une phrase détachée, mais qui déploie aussi toute sa masse textuelle pour nous faire entrer dans ce récit énigmatique et confidentiel - comme si le lecteur savait déjà ce qui était arrivé, et reconnaissait l'histoire ; comme s'il s'agissait d'une amitié au cours de laquelle on s'était beaucoup parlé et où tout le monde se connaissait à la différence toutefois que l'histoire ici est racontée de manière inhabituelle - ou plutôt que les récits au pluriel, en état de véritable fourmillement, interrompus, fissurés, fragmentés et prolongés vers 
différentes directions, épousent la tentative folle d'un sujet qui veut être partout en même temps.

Le livre de Simon abonde en caractérisations sonores ; ces bruits font partie des faits de la vie quotidienne et de ce qui est quotidien aussi, mais qui ne tient pas de la vie mais du désastre, des destructions, de la mort, donc de la guerre et comme il y a beaucoup de sons, il y a aussi beaucoup de couleurs, décrites de façon raffinée, tout en nuances, tirées de cartes postales, dans une sorte d'ekphrasis, où entre seulement le jeu de la lumière et de l'ombre ; des observations rapides comme l'éclair faites partout dans le monde physique pour ne pas oublier tous les objets qui existent et leurs couleurs, ou seulement un gris saturé sur l'emballage d'éléments particuliers ; voici un livre élaboré tout à la fois pour les oreilles et pour les yeux : faites attention alors au fait que les sauts du livre, déployés, interrompus, par voies d'associations, continuent et continuent encore selon un dessein incalculable ou selon un dessein qui lui aussi est comme brisé ; tout se fend et tout continue ; voici un livre qui traite de la nature tactile des matières et de la rencontre du corps avec le monde physique ; tous les livres de Simon sont tournés vers la terre, mais plus que tout, nous avons affaire ici à un livre centré sur la phrase, un livre si délibéré et si bouleversant que toutes les tentatives de le voir comme un acte de spontanéité ou le fruit du hasard sont tout simplement insensées ; même avec des sens éclairés par plusieurs lampes puissantes, l'intellect nous dit que ce livre expert, énigmatique et rusé demande qu'on le lise avec une très grande attention.

L'ouverture du livre, le commencement de la phrase fissurée n'est que le prolongement de quelque vaste flux qui continue à la manière du courant rapide d'une rivière devant des obstacles accidentels, de sorte que le début du livre aurait pu se trouver partout, comme si le livre n'avait pas de véritable début mais proposait seulement la continuation de ce qui a déjà commencé, et le prolongeait par ce qui lie ou semble lier l'ensemble, puisque, de tous les côtés, tout est dispersé et brouillé, tous ces fragments textuels de nature différente, peut-être une série de vieilles cartes postales venues d'Afrique, d'Arabie ou d'Asie ou bien le moment précis où le narrateur, un soir, travaille assis devant la fenêtre ouverte, regardant un acacia ; la lumière de la lampe fait briller le feuillage et une petite brise le fait trembler comme s'il murmurait, un murmure polyvalent ou un tremblement 
traversant la masse des feuilles ; comme si du feuillage qui jouxte le tronc aux feuilles les plus éloignées un chœur dormant semblait s'éveiller, et ainsi s'éveille l'histoire du narrateur, ou s'est-elle éveillée pour continuer à être réveillée selon de lents déplacements, comme des blocs de paragraphes dépliant l'une après l'autre des phrases à la mesure d'un désir fou de tout dire à la fois. 